\title{
Nanomole per Minute per Milliliter
}

National Cancer Institute

\section{Source}

National Cancer Institute. Nanomole per Minute per Milliliter. NCI Thesaurus. Code C92613.

A unit of concentration (molarity unit) equal to one billionth of a mole (10E-9 mole) of solute per minute per milliliter. 